\title{
Improving efficiency of seed system by appropriating farmer's rights in India through adoption and implementation of policy of quality declared seed schemes in parallel
}

\begin{abstract}
Indian agriculture is dominated by the marginal and small farmers with very small average land holding size which is further fragmented and scattered into tiny pieces. Contemporary challenges being faced by Indian agriculture are increasing population pressure, diminishing natural resources (land, water and agro-biodiversity), increasing demand of diversified diets, increased frequencies of extreme climate change and increasing cost of production are keep on haunting. To increase production and productivity and to mitigate the adverse effect due to climate change, the regular and timely supply of quality seed of all crops and varieties at affordable prices at local level is prerequisite. The formal seed sector, although contributes in significant manner to make available the quality seed but is not in position to cater the demand of farmers at local level and therefore necessitates the quality seed production and distribution locally by involving farmers. In the present commentary issues have been discussed with regard to the adoption and implementation of quality declared seed policy of the Food and Agriculture Organization of the United Nations in parallel. The QDS policy can easily accommodate and integrate the registered farmers varieties as per PPV\&FR Act (2001) into seed chain effectively and efficiently.
\end{abstract}

Keywords: quality declared seed, intellectual property rights, varietal diversity \& seed security
Volume 3 Issue 6 - 2018

\author{
Singh RP,' Agrawal RC \\ 'Director Seed \& Farms, Birsa Agricultural University, India \\ ${ }^{2}$ Registrar General, Protection of Plant Varieties and Farmers \\ Rights Authority, India
}

Correspondence: Singh RP, Director Seed \& Farms, Birsa Agricultural University, Kanke, Ranchi-834006, Jharkhand, India, Email dsfbeu@rediffmail.com

Received: April 30, 2018| Published: December 14, 2018

\section{Introduction}

Food security is dependent on seed security and ensuring the timely availability of quality seed in desired quantity at right time at appropriate price is fundamental to increase production and productivity. Increasing population pressure, diminishing natural resources, increased frequencies of extreme events due to climate change further aggravate the problems. With these challenges the country needs to double its food production due to increased income and diversification of diets by 2050. Marginal and small farmers grow more number of crops and varieties in different cropping systems as mono-crop as well as mixed cropping and their most important contribution in creating, conservation and maintaining agrobiodiversity is crucial for smallholders to create resilience to climate change effects as it creates capacity to absorb shocks and adapt to changing sets of circumstances as per observation made by FAOOECD. ${ }^{1}$ The paper leads to the conclusion that parallel implementation of the FAO policy of Quality declared seed system can increase diverse seed access by marginal and small holders in India at local level in order to improve seed systems resiliency in parallel to normal seed regulatory system for protecting varietal diversity and ensuring food security in India.

\section{Formal vs informal seed sectors}

In India, quality seeds of high yielding varieties (HYVs) along with fertilizers and irrigation brought green revolution and therefore recognizing the crucial role played by quality seed as critical input factor upon which the performance of other input factors (agrochemicals, irrigation and mechanization etc.) depend heavily to increase production and productivity and the seed of notified varieties is mainly supplied by the formal seed sector. This production system is ideally suited for high input production environments. India ranks first, with 179.8 Mha of net cropland area (9.6 percent of the global net cropland area) according to United States Geological Survey 2017 according to the Economic Survey of India 2017-18. ${ }^{2}$ In India, $67 \%$ of total holdings are by marginal farmers with average holding of just 0.39 ha, and $17.9 \%$ small farmers with average farm size of 1.42 ha. Altogether, marginal and small farmers possess $85 \%$ of total holdings and cultivate $44.6 \%$ area with average farm size of just 0.6 ha. Although, globally India seed industry ranked 5th largest player with the robust growth, but domestically, only $24 \%$ sub-marginal and $29 \%$ marginal farmers replace seed every year against $40 \%$ by large farmers. Overall, access to quality seed by small and marginal farmers is reported to be only $20 \%$ as reported by Roy. ${ }^{3}$ The informal seed sector comprising mainly farm-saved seed (FSS), which accounts $65-70 \%$ according to the department of agriculture co-operation and farmers welfare report $2016^{4}$ emphasizes the need to strengthen the seed system's resilience at local level. National Mission on Seeds emphasized to improve quality of farmers own seed with increased seed replacement rates (SRRs) are required to increase production and productivity recognized by the then Planning Commission ${ }^{5}$ now renamed as NITI AAYOG. Seed security is pre-requisite to food security and according to the 70th Round of National Sample Survey (2012-13), at all India level, average expenditure on crop production per cultivating agricultural household, about $24 \%$ of the expenditure was made on fertilizers and manures, $21 \%$ on human labor and nearly just $11 \%$ of the total expenditure made on seeds (NSSO). ${ }^{6}$ Therefore, having the lowest cost of seed as input with relatively high output, 
has been established that in India, through quality seed alone, $20-25 \%$ higher productivity can be obtained. The formal seed sector in India contributes only about $30-35 \%$ of the total seed requirement in India while informal seed sector's contribution is enormously high, mainly in the form of farmer's own seed and commonly known as FSS to the tune of $65-70 \%$ (DAC \& FW 2016 $)$, thereby reflecting low seed replacement rates (SRRs). Similarly, on the basis of input survey (201112), conducted by the Agricultural Census Division of "Department of Agricultural Cooperation and Farmers Welfare" (DAC\&FW), Ministry of Agriculture and Farmers Welfare's (Government of India) published report in 2016, out of a total of 138.11 million operational holdings, only $39.41 \%$ used certified seeds while $26.96 \%$ used seeds of notified varieties, ${ }^{7}$ clearly establishes the fact that in addition to the poor SRRs, the varietal replacement rates (VRRs) are even more poor. Furthermore, on the basis of survey report it can be safely concluded that, although the adoption of first or initial generation of modern high yielding varieties was very high, but second third or fourth generation's improved varieties were less adopted which ultimately culminated into poor varietal replacement rates stressing that farmers are still using either old high yielding varieties (HYVs) developed and deployed during green revolution (GR) era. ${ }^{8-10}$

\section{The quality issues of the farm saved seeds (informal seed sector)}

With respect to the seed health status of farmers' own (saved) seed among cereals and legumes which are extremely important for food and nutritional point of view, the studies conducted during 2017-18 reveals that In case of rice bunt pathogen (Tilletia barclayana) in 372 varieties from farmers and processing plants from 16 states, $24.7 \%$ samples were found to be infected with rice bunt pathogen which were collected from Punjab, Haryana, Uttrakhand, Uttar Pradesh and Himachal Pradesh states from north western India. Moreover, in rice, the problem of seed discoloration was also observed which was caused by the infection due to a number of mycoflora (Helminthosporium oryzae, species of Drechslera, Fusarium, Curvularia, Alternaria etc.,) and ultimately resulted in drastic reduction of seed germination below the seed certification standards. Nevertheless, in wheat also the investigations on seed health status of farmers saved seeds from seven states confirmed the alarming association of Karnal bunt (Tilletia indica) of wheat in Punjab, Haryana and Himachal Pradesh. In case of oilseeds, legumes and Soybean the studies on seed health of FSS revealed the association among Macrophomina phaseolina, Fusarium oxysporum and Colletotrichum dematium with soybean seed found to be widespread in Madhya Pradesh, Maharashtra, Telangana and Rajasthan states of the country while in another legumes, Groundnut FSS, the dominant association of Aspergillus flavus was recorded as a widespread problem in Maharashtra, Madhya Pradesh and Gujarat states. Similarly, in case of pulse legumes, in Chickpea FSS samples widespread infection of Fusarium oxysporum was observed. Furthermore, study also revealed that about $45.5 \%$ FSS samples were infested with various storage pests, $40 \%$ seed samples possessed germination below Indian Minimum Seed Certification Standards (IMSCS) and above $33.2 \%$ samples exhibited insect damage beyond permissible limit. ${ }^{11}$

Also, the size of FSS is not uniform and frequently under size or shriveled grains also being used as seed. Due to the presence of various seed and/or airborne pathogens and storage pests the quality of FSS is not according to IMSCS standards which ultimately culminate in poor germination and poor crop plant stand particularly, in rainfed/marginal conditions and thus significantly effecting yield and quality. India ranks first among the rainfed countries in the world by having 78 million hectares and thus constituting 64 per cent of the country's net sown area being rainfed, but in terms of productivity, its position is amongst the lowest (nraa.gov.in). Upland rice in India covers approximately six million hectares grown mostly under rainfed conditions through direct sowing in which relatively high seed rate $(75-80 \mathrm{~kg} / \mathrm{ha})$ is required. Mainly in upland rice traditional/farmers varieties dominate the scene. With regard to pulses and oilseed crops which are grown under rain-fed conditions, viz Chickpea, Groundnut and Soybean in particular which tend to have higher seed rates (80$100 \mathrm{~kg} / \mathrm{ha}$ ) and low seed multiplication rates (SMRs), leading to higher seed prices and relatively higher seeding costs, which again makes poor SRR and VRR and make farmers to go for FSS. Re-sowing and/ or gap filling further increase the requirement of quality seed in these areas. Altogether, these factors therefore, necessitates to improve the quality of farmers saved seed of informal seed sector which has more than two third share in order to improve the production and productivity thereby ensuring food security.

Contemporary literature on seed supply systems refers to seed as either 'modern varieties' (MVs) which are improved by organized breeding programs or local varieties (LVs) popularly known as landraces, which have never been subjected to a formal plant breeding program. In India, farmers grow different kind of varieties such as modern high yielding varieties, hybrid, traditional/farmers/landraces/ local varieties etc., depending upon their domestic/commercial requirements and availability of input resources particularly irrigation in different seasons. Farmers do recognize the peculiar characteristics of MVs such as novel resistances, and identify characters, particularly taste, processing qualities and resilience in sub- optimal conditions ${ }^{12}$ which are prevalent most of the times due to climate change effects. The LVs still cover significant area and virtually grown in all regions and seasons in the country. The adoption and diffusion of one kind of variety in a particular season and total absence of another kind in the same state, like in Odisha where in rice during summer season only MVs are grown while in Bihar state during Bhadai (autumn) season only LVs are grown, in maize which is grown round the year in different seasons in Bihar both MVs and LVs are cultivated during Bhadai and Garma (summer) seasons but during rabi (winter) season only LVs are grown recognizing the adoption pattern of MVs being highly asymmetrical in different seasons in same region and in different region in the same season ${ }^{13}$ (Singh et al. 2016), and for productivity levels, it was revealed that, under marginal conditions the performance of LVs is comparable and even these varieties can out yield MVs, but under favorable environment with high input and better management conditions MVs performed extremely well and therefore highly responsive to inputs. Moreover, the yield gains obtainable through MVs over LVs, varies from season to season in the same region and in different regions in the same season including the variability in yield which also varies according to kind of varieties and seasons. ${ }^{9}$

\section{Appropriating farmer's rights in India through protection, promotion and commercialization of farmers' varieties}

In the web of intellectual property rights (IPRs), while plant variety protection (PVP) focuses on new plant varieties, India has adopted a unique (sui generis) PVP system in the form of Protection 
of Plant Variety and Farmers' Rights (PPV\&FR) Act, 2001 which includes other categories of varieties that are not necessarily novel as required under the UPOV Convention. Indian PPVFR Act allows for the registration of extant and farmers' varieties that are not novel, but it requires that they conform to the distinctness, uniformity and stability (DUS) criteria. Dropping the novelty requirement (which is essential under PVP legislation) may significantly expand the range of varieties eligible for protection since those varieties that have been offered for sale or commercialized at any time before an application for protection is filed are eligible for protection. Generally, in formal seed sector, only varieties having passed DUS and value for cultivation and use (VCU) and duly released and notified as per seed act 1966 inducted into seed production chain and many FVs are unable to meet the DUS requirement. Although India has amended through regulation for furtherance of the implementation of the PPV\&FR Act 2001, stipulating that for FVs uniformity standard could be relaxed to allow double the number of off-type as otherwise permitted for registration of other categories of varieties under that act. ${ }^{14}$ This act provides a balance between plant breeders' rights along with farmers' rights and researchers' rights and also recognizes the contribution of both commercial plant breeders and farmers in plant breeding activity. ${ }^{15}$ The farmers are exempted to pay any kind of fee to register their varieties. The plant breeders' rights granted on Farmers varieties provides the exclusive right to produce and market the seeds of registered varieties. A farmer under Indian PPV\&FR Act has rights is entitled to save, use, sow, re-sow, exchange, share or sell his farm produce including seed of a variety protected under the Act, but not entitled to sell seeds of a protected variety in a branded manner.

The crop wise analysis with respect to the granting of PVP certificates under PPV\&FR Act till April 2018 (plantauthority.gov.in/) revealed that In case of cereals and coarse cereals, ten FVs had been given PVP certificates in wheat, while six FVs in maize, and four in sorghum were given PVP certificate by the Authority but highest number of FVs in Rice (1262) were protected through legislation and altogether, 1305 farmers varieties $(42.7 \%)$ were provided PVP protection out of total 3121 protected varieties. In cereals and coarse cereals group, FVs occupied first rank (58\%) as compared to public sector $(17 \%)$ and private sector $(25 \%)$. In other crop groups, FVs lagged behind with public and private and only a marginal number of varieties could be registered in legumes (6), oilseed (7) and spices (9) crop groups. The farmers have almost all PVP certificates in the group of food grain crops (cereals and pulses) which have low SRR. Seed regulatory system is not designed to promote commercialization of LVs/FVs. The applications filed by farmers tops the list (10793) which is $66 \%$ of the total applications filed by all stakeholders (16317) including private and public.

In India, a variety needs to be released and/or notified by the Government to be introduced into the formal seed system which is based on the DUS plus VCU criteria. To integrate these varieties in formal seed system it has been suggested that these varieties needs to be accommodated in the varietal registration system by relaxing "looser" identification criteria. ${ }^{16}$ Nevertheless, Serpolay-Besson et al. ${ }^{17}$ argued that very heterogeneous (genetically) nature of open pollinated varieties (OPVs) is an asset for farmers as they are found to be resilient in the specific local conditions and advocated for farmer OPVs should receive more support through social and regulatory recognition. Currently, the peculiar types of standards are being framed with great biasedness and may have consequences for food security and agro-biodiversity conservation. Initially, seed certification and quality control programs were evolved in order 'to help farmers who bought seed, since both the variety and the quality of the seed cannot be judged by merely a visual inspection of the seed itself. ${ }^{18}$

\section{Improving seed quality of farm saved seed by adopting and implementing the fao policy of quality declared seed schemes}

To take the full advantage of the rich genetic diversity in the form of LVs/FVs an alternative registration and certification system developed by the Food and Agriculture organization of the United Nations known as Quality Declared Seed (QDS) system is advocated to channelize and commercialize LVs using formal system. ${ }^{19}$ The QDS is an alternative way to reach small farmers who do not have access to, and so do not use, certified seed for crop production. The QDS system being semi formal and less costly and less stringent as compared to conventional seed certification with the focus on local seed trade. Specifically, the adoption of QDS would give practical effect to Article 5 (Conservation, Exploration, Collection, Characterization, Evaluation and Documentation of Plant Genetic Resources for Food and Agriculture) and Article 6 (Sustainable Use of Plant Genetic Resources) of the International Treaty on Plant Genetic Resources for Food and Agriculture (ITPGRFA) including a number of Activities of the Global Plan of Action (GPA) for conservation and sustainable utilization of PGRFA. Categories of varieties included under QDS system are (i) conventional varieties developed through informal seed systems (ii) local/farmers varieties and (iii) varieties developed through alternative plant breeding approaches such as participatory plant breeding according to the Food and Agriculture Organization of United Nations. ${ }^{20}$ The Indian PVP system under Protection of Plant Varieties and Farmers Rights Act $^{21}$ is altogether different, because under this Act a variety can be registered under either of four categories: new variety, essentially derived varieties, extant variety and farmers' variety.

National Seeds Policy, ${ }^{22}$ while protecting the interests of farmers through conservation of agro-biodiversity emphasized to increase seed replacement rates (SRRs), which will need a quantum increase in quality seed production. To accomplish the task, in its xii ${ }^{\text {th }}$ plan submission on seeds and planting material, the Ministry of Agriculture and Farmers Welfare initiated the "National Mission on Agricultural Extension and Technology" with the objective to improve overall seed sector and seed supply chain in India. Among other objectives of the sub-mission, SRRs have been increased from 25 to $33 \%$ in case of self-pollinated crops(SPCs), 33 to $50 \%$ in case of cross-pollinated crops (CPCs) and $100 \%$ in hybrids is the most significant ${ }^{4}$. On the other hand, farmers continuously create new variability in the form of farmers/local varieties which are preferred over MVs such as in rabi sorghum where almost 80 years old FVs dominate the scene and covered $>80 \%$ area, both varieties and seed replacement rates (VRRs \& SRRs) are also decreasing. Moreover, in the developing countries including India, modern high yielding varieties of initial generations have also been improved and/or modified by farmers according to their choice and ultimately these varieties got adapted in different agroecological regions having different vernacular names and contributing significantly, although most of the earlier generation MVs do not find place in the active informal seed chain but their incorporation into traditional systems may lead to the genetic integration of MVs and TVs and the process by which modification of MVs by TVs takes place is known as Criolloization ${ }^{23}$ or Rustication, ${ }^{24}$ which appear to 
be universal. In this process, MVs exchange genes with landraces and valuable features of MVs get integrated through farmers management, with desirable features of traditional varieties. ${ }^{25}$

The quality seed production and distribution of these varieties at local level is of paramount importance to mitigate the climate change effects. In this scenario, the QDS, being less ambitious and more incremental ${ }^{26}$ can also be adopted along with the seed system having stricter standards confirming DUS as preconditions for variety registration and a second tier that establishes a QDS system adopted by country like Zambia. ${ }^{27}$ This system has also been adopted in other countries like Ecuador, Peru, Ethiopia, Uganda, and Tanzania. Importantly, QDS systems can be less costly than conventional certification systems. Under India's National Food Security Mission (NFSM) consideration for QDS finds mention ${ }^{28}$ which need to be implemented on priority basis in order to enhance diverse seed access (in terms of increased varietal and seed replacements) by marginal and smallholder vis-a vis strengthening seed system at local level. Also, production, productivity and adaptability due to climate change events would be increased.

Climate change also affects the seed crop seed yield, and ultimately seed quality. ${ }^{19}$ Genetic diversity and breeding for improved stress-tolerant genotypes are key elements in tackling climate change. Plant genetic resources (PGRs) are important sources for developing new and improved varieties. The loss of these genetic resources due to climate change will deprive source of diversity and tolerance. ${ }^{29}$ Therefore, farmers being the custodians of agro-biodiversity need to be involved in varietal selection and their seed production at local level. The Seed Systems Resiliency can be improved at local level through participatory approach for adaptation and mitigation to climate change. ${ }^{30}$ Finally, integration and commercialization of local varieties under sub-optimal environments for food security and agrobiodiversity conservation can be enhanced through participatory approach in order to promote sustainable agriculture. ${ }^{31}$ The local varieties could be commercialized by adopting and implementing the FAO policy of Quality declared seed system in parallel to increase diverse seed access by marginal and small holders in India at local level in order to improve seed systems resiliency in parallel to normal seed regulatory system for protecting varietal diversity and ensuring food security in India.

\section{Acknowledgments}

None.

\section{Conflicts of interest}

Author declares there is no conflicts of interest.

\section{References}

1. FAO-OECD. Sustainable agricultural productivity growth and bridging the gap for small family-farms. Interagency Report to the Mexican G20 Presidency. 2012

2. Economic Survey. Climate, Climate Change, and Agriculture. 2017:82101.

3. Roy TN. Review on access of small and marginal farmers to improved seeds in India. Economic Affairs. 2015;60(4):713-719.

4. DAC \& FW. State of Indian Agriculture 2015-16. Department of Agriculture, Cooperation \& Farmers Welfare, Directorate of Economics and Statistics, Ministry of Agriculture \& Farmers Welfare, New Delhi: Govt. of India; 2016. 280 p
5. Planning Commission. An Approach to the Twelfth Five Year Plan (2012-17). Govt. of India; 2011. 146 p.

6. NSSO. Income, Expenditure, Productive Assets and Indebtedness of Agricultural Households in India. NSS 70th Round, GOI, Report No. $576(70 / 33 / 3) .2016 .1605 \mathrm{p}$

7. DAC \& FW. All India Report on Input Survey 2011-12, Agriculture Census Division, Ministry of Agriculture and Farmers Welfare. New Delhi; 2016. 521 p.

8. Singh RP. Varietal replacement rates among field crops: current status, constraints, impact, challenges and opportunities for the Indian seed industry. Seed Times (National Seed Association of India). 2015;7(3\&4):71-89.

9. Singh RP, Agarwal DK, Rajendra Prasad S, et al. Varietal and seed replacement in the era of climate change. Mau, UP, India: Indian Council of Agricultural Research -Indian Institute of Seed Science (ICAR-IISS); 2017.

10. Singh RP. Appropriating varietal and seed replacement raters through policies for sustainable agriculture and seed industry. Sri Lanka: Souvenir Indian Seed Congress; 2018:120-135.

11. IISS. Annual report: Glimpses 2017-18. AICRP National Seed Project (Crops). Kushmaur, Mau: ICAR-Indian Institute of Seed Science, -275103 (UP); 2018.53 p.

12. Salazar R, Louwaars NP, Visser B. CAPRi Working Paper \# 45 . International Food Policy Research Institute (IFPRI), $2033 \mathrm{~K}$ Street, Washington DC, USA. 2006.

13. Singh RP, Kumar A, Pal, SK. The prevalence, productivity and protection of traditional varieties vis-à-vis modern varieties in Eastern India: An appraisal. Jharkhand Journal of Development and Management Studies. 2016;14(2):6955-6970.

14. GOI. Government of India, the Gazette of India Extraordinary. 2009.

15. Hanchinal RR, Agrawal RC, Ravi Prakash, et al. Impact of awareness programmes and capacity building in Farmers' Plant Variety Registration under the PPV\&FR Act. Journal of Intellectual Property Rights. 2014;19:347-352.

16. Srinivasan SC. Institutional capacity and implementation issues in farmers' rights. In: Halewood H, editor. Farmers' crop varieties and farmers' rights: Challenges in taxonomy and law. Issues in Agricultural Biodiversity. 2016:249-281.

17. Serpolay-Besson E, Giuliano S, Schermann N, et al. Evaluation of Evolution and Diversity of Maize Open-Pollinated Varieties Cultivated under Contrasted Environmental and Farmers' Selection Pressures: A Phenotypical Approach. Open Journal of Genetics, 2014;4:125-145.

18. Louwaars N. Biases and bottlenecks: time to reform the South's inherited seed laws? 2005.

19. Singh RP, Prasad PVV, Reddy KR. Impact of changing climate and climate variability on seed production and seed industry. Advances in Agronomy. New York: Academic Press; 2013;118:49-110.

20. FAO (2006). Food and Agriculture Organization of the United Nations, Quality Declared Seed System. FAO Plan Production and Protection Paper 185. Rome: FAO, 2006.

21. The protection of plant varieties and farmers' rights act. 2001.

22. National seeds policy. 2002

23. Lamola LM, Bertram RB. Experts gather in Mexico to seek new strategies in preserving agro-biodiversity. Diversity. 1994;10:15-17.

24. Prain G. Mobilizing local expertise in plant genetic resources research. In: de Boef WK, Amanor K, Wellard, Bebbington A, editor. 
Cultivating Knowledge: Genetic Diversity, Farmer Experimentation and Crop Research. London: Intermediate Technology Publications; 1993:102-110.

25. Wood D, Lennea JM. The conservation of agrobiodiversity on-farm: questioning the emerging paradigm. Biodiversity and Conservation. 1997;6(1):109-129.

26. Bishaw Z, Louwaars N. Evolution of seed policy and strategies and implications for Ethiopian seed systems development. In: Wold AT, Fikre A, editors. Defining moments of Ethiopian seed sector. Ethiopia: Ethiopian Institute of Agricultural Research; 2012

27. Halewood M, Lapena I. Farmers' varieties and farmers' rights. In: Farmers' crop varieties and farmers' rights; Challenges at the crossroads of agriculture, taxonomy and law edited by Michael Halewood, Bioversity International. Taylor and Francis; 2016:1-24.
28. Spielman DJ, Smale M. Policy Options to accelerate Variety Change among Smallholder Farmers in South Asia and Africa South of the Sahara, Environment and Production Technology Division. IFPRI; 2017. 68 p.

29. Singh RP, Prasad PVV, Reddy KR. Climate Change: Implications for Stakeholders in Genetic Resources and Seed Sector. Advances in Agronomy, New York: Academic Press; 2015;129:117-180.

30. Singh RP. Improving Seed Systems Resiliency at Local Level through Participatory Approach for Adaptation to Climate Change. Adv Plants Agric Res. 2017;6(1):15-16.

31. Singh RP. Integration and commercialization of local varieties under sub-optimal environments for food security, promoting sustainable agriculture and agro-biodiversity conservation. MOJ Eco Environ Sci. 2018;3(2):65-67. 